\title{
Leader
}

\section{Human papillomavirus and the development of non-melanoma skin cancer}

\author{
Catherine A Harwood, Jane M McGregor, Charlotte M Proby, Judith Breuer
}

\begin{abstract}
Human papillomaviruses (HPV) are increasingly recognised as important human carcinogens. The best established association with human malignancy is that of high-risk mucosal HPV types and anogenital cancer. HPV-induced transformation of anogenital epithelia has been the subject of intense research which has identified the cellular tumour suppressor gene products, p53 and pRB, as important targets for the viral oncoproteins E6 and E7 respectively. Certain HPV types are also strongly associated with the development of non-melanoma skin cancer in the inherited disorder epidermodysplasia verruciformis (EV). However, in contrast with anogenital malignancy the oncogenic mechanisms of EV-HPV types remain uncertain, and there appears to be a crucial additional requirement for ultraviolet radiation. Cutaneous HPV types in the general population are predominantly associated with benign viral warts, but a role in non-melanoma skin cancer has recently been postulated. Polymerase chain reaction based HPV detection techniques have shown a high prevalence of HPV DNA, particularly in skin cancers from immunosuppressed patients and to a lesser extent in malignancies from otherwise immunocompetent individuals. No particular HPV type has yet emerged as predominant, and the role of HPV in cutaneous malignancy is unclear at present. It remains to be established whether HPV plays an active or purely a passenger role in the evolution of non-melanoma skin cancer. (f Clin Pathol 1999;52:249-253)
\end{abstract}

Keywords: human papillomavirus; non-melanoma skin cancer

Non-melanoma skin cancers are the most prevalent malignancies in fair skinned populations worldwide. ${ }^{1}$ They account for up to one third of all cancers in the USA, and in Australia the estimated incidence is twice that for all other cancers combined. ${ }^{2}$ While the mortality is low (545 deaths in the United Kingdom in 1991), the associated morbidity is significant, as is the burden on health care provision. Epi- demiological and molecular data implicate ultraviolet radiation as the most important aetiological factor, ${ }^{3-5}$ but other agentsincluding the immune response, genetic predisposition, and viral infection-are also likely to be involved. Several viruses have been implicated in the development of non-melanoma skin cancer, but the most plausible evidence to date is that for human papillomavirus (HPV).

$\mathrm{HPV}$ are increasingly recognised as important human carcinogens: overwhelming evidence from both epidemiological and functional studies implicates high risk mucosal HPV types in cervical and other anogenital cancers. ${ }^{6}$ A role for HPV in cutaneous malignancy is also proposed in the rare inherited condition epidermodysplasia verruciformis, which is characterised by a predisposition to HPV infection and the development of cutaneous squamous cell carcinomas on sun exposed sites. ${ }^{7}$ However, until recently it has proved technically difficult to detect HPV DNA in skin cancers and this has hindered research in the area. With the introduction of polymerase chain reaction (PCR) based techniques, several groups now report a high prevalence of HPV DNA in non-melanoma skin cancers in both immunosuppressed and non-immunosuppressed patients, providing new impetus for research. ${ }^{8-12}$

In this review we summarise the biology, epidemiology, and functional data on HPV that are potentially relevant to skin carcinogenesis.

HPV structure and life cycle

The papillomavirus family embraces an heterogeneous group of double stranded DNA viruses consisting of approximately $8000 \mathrm{nu}-$ cleotide bases. The general organisation of the genome is the same for different HPV types and consists of three main regions: the "early" (E) region encoding viral regulatory, transforming, and replication proteins; the "late" (L) region encoding the structural capsid proteins L1 and L2; and the non-coding or upstream regulatory region. The HPV encoded early genes appear to have multiple functions including (E1) ATPase and helicase activity necessary for initiating viral replication, (E2) regulation of viral transcription and replication, and (E4) proteins involved in maturation and release of viral particles. E5 has some
Accepted for publication 11 August 1998 
transforming potential but this is not fully characterised, while E6 and E7 are the major transforming proteins of genital HPV.

HPV infects basal epithelial cells, stimulating epithelial proliferation. In benign viral warts it is present as episomal DNA with low level replication of viral episome within basal keratinocytes maintained by E1 and E2 expression. The full vegetative life cycle of HPV is tightly linked to keratinocyte differentiation, and other viral early genes are not switched on until the infected keratinocyte leaves the basal layer. Late gene expression with production of virus particles can only take place in highly differentiated keratinocytes.

\section{Classification, phylogeny, and detection of HPV}

Until recently difficulties in producing adequate keratinocyte differentiation in vitro hindered development of culture systems for viral propagation, and serology proved less useful for HPV detection than for other viral infections. Consequently, improvements in HPV detection techniques coincided with the advent of recombinant DNA technology. Distinguished originally by its restriction enzyme map, a papillomavirus isolate is now classified exclusively by characterisation of its genome; a new type is one in which the nucleotide sequence of the most highly conserved part of the HPV genome, the L1 open reading frame (ORF), is shown to share less than $90 \%$ identity to the homologous sequences of established prototypes. ${ }^{13}$ Based upon this definition, 80 distinct HPV genotypes have now been described, but several groups have identified and partially characterised novel sequences predicting the existence of many more. ${ }^{6}$ Papillomaviruses show a marked host and epithelial cell specificity for infection and historically they have been grouped according to the location and clinical context from which they were initially isolated, hence the terminology "cutaneous," "mucosal," and "epidermodysplasia verruciformis" types. Subsequent phylogenetic analyses based on sequence information have broadly justified this clinical classification. ${ }^{14}$

The genomic diversity of the many different $\mathrm{HPV}$ poses a considerable challenge to HPV detection and genotyping. Methods based upon DNA hybridisation to specific HPV probes (Southern blot, slot blot, in situ hybridisation) have now largely been superseded by PCR based techniques using degenerate and nested primers to increase sensitivity and specificity. This has revealed a diverse range of HPV in skin and mucosal tissue, including HPV sequences which probably represent new, as yet uncharacterised types. ${ }^{8-12}$

\section{Models of HPV associated skin carcinogenesis}

EPIDERMODYSPLASIA VERRUCIFORMIS (EV)

In 1922, long before the association of HPV with cervical carcinoma was suspected, an association between warts and skin cancers was observed in patients with epidermodysplasia verruciformis. ${ }^{15}$ Epidermodysplasia verruciformis predisposes to widespread skin warts with an average age of onset of six years. The warts are clinically unusual and include red-brown plaques and scaly pityriasis versicolor-like lesions, in addition to extensive plane and common warts. ${ }^{7}$ Squamous cell carcinomas develop on light exposed sites in $30-60 \%$ of affected patients by the fourth decade, and specific HPV types, predominantly HPV-5 and HPV-8, are found in over $90 \%$ of these tumours. ${ }^{16}$ The basis of this disorder is unknown but may involve alteration of viral regulatory pathways at the level of the keratinocyte. Partial defects in cell mediated immunity have been demonstrated but remain poorly defined. ${ }^{717}$

Despite the apparent strength of the association between HPV-5/8 DNA and epidermodysplasia verruciformis associated cutaneous squamous cell carcinoma, there are currently few data on mechanisms of viral transformation. Compared with high risk mucosal HPV, the transforming potential of EV-HPV in vitro is low. ${ }^{18}$ Although HPV-8 E6 transformed rodent fibroblasts cannot induce tumours in nude mice, morphological transformation, anchorage independence, and reduced serum requirement can be demonstrated and this activity is found to reside mainly in the E6 ORF. ${ }^{19}$ The E7 ORF, in marked contrast to HPV-16/18 E7, has little independent transforming activity. Similar results have been observed for HPV-47. ${ }^{20}$ To date it has not been possible to immortalise human cells using EV-HPV. Interactions between E6 and p53 or E7 and pRB used by HPV16/18 cannot be demonstrated for the EV-HPV. ${ }^{21}$ A possible transforming mechanism is the transregulation function encoded by $\mathrm{E} 2$ which activates regulatory elements within the upstream regulatory region of oncogenic EV-HPV types. ${ }^{22}$ This may result in enhancement of gene transcription during early stages of malignant progression. ${ }^{23}$ It is currently believed that EV-HPV may act only as co-carcinogens with an absolute requirement for ultraviolet light. This may explain the failure to date to show in vitro transformation of human keratinocytes using EV-HPV alone.

NON-MELANOMA SKIN CANCER IN IMMUNOSUPPRESSED INDIVIDUALS

Organ transplant recipients

For over 25 years, an association between virus warts and skin cancer has been suspected in renal transplant recipients. ${ }^{24}$ Renal transplant recipients have a well documented 50- to 100fold increased risk of cutaneous squamous cell carcinoma in particular, ${ }^{25}$ and a reversal in the normal squamous cell to basal cell carcinoma ratio. ${ }^{2426}$ The cumulative incidence of skin cancer is $27-44 \%$ after $10-25$ years of immunosuppression, ${ }^{27-29}$ and clinical and histological features of transplant squamous cell carcinoma indirectly support the progression of virus warts through increasingly dysplastic squamous lesions to invasive squamous cell carcinoma. ${ }^{30-33}$ Viral warts and cutaneous squamous cell carcinoma colocalise on sun exposed sites and ultraviolet light appears to be 
an important factor in the development of both warts and cancers. ${ }^{32}$

HPV DNA prevalence-In early studies of $\mathrm{HPV}$ in non-melanoma skin cancer from transplant recipients, detection of HPV DNA varied considerably both in overall prevalence (from 0-64\%) and in the HPV types detected. ${ }^{34}$ These discrepancies are likely to reflect the detection methods used. ${ }^{35}{ }^{36}$ More recent studies using degenerate PCR consistently show a higher prevalence (65-81\%) of HPV DNA in transplant tumours, although the spectrum of HPV types detected differs considerably. ${ }^{8-12}$ The nested PCR method developed by Berkhout et $a l^{1011}$ detected epidermodysplasia verruciformis or EV related viruses in 49 of 61 squamous cell carcinomas (80\%), four of eight basal cell carcinomas, 14 of 15 actinic keratoses, and two of five in situ carcinomas. In a separate study, Shamanin et al found identifiable HPV types in 13 of 20 squamous cell carcinomas and three of five basal cell carcinomas, ${ }^{9}$ but only $20 \%$ of the HPV types were EV associated; the majority consisted of either high risk mucosal types (HPV-16, -51, $-54,-56,-61$, and -69) or cutaneous types (HPV-41 and -60). Again these discrepancies are likely to reflect the PCR primers employed. Confirmation of this is provided in a recent study ${ }^{12}$ in which lesions initially analysed using the PCR primer panel described by Shamanin et $a l^{9}$ were shown to contain predominantly cutaneous types. However, additional EV-HPV types were detected when the same lesions were reassessed using the nested primer pair of Berkhout et al. ${ }^{10}$

Our group has since extended the degenerate PCR methodology to include nested primer pairs for mucosal and cutaneous HPV as well as EV-HPV. ${ }^{35}$ We have found a high prevalence of HPV in premalignant and malignant skin lesions from transplant patients (unpublished data): HPV DNA was detected in 39 of 47 squamous cell carcinomas (83\%), 15 of 23 basal cell carcinomas, and 17 of 18 premalignant skin lesions. EV-HPV types were found in over $80 \%$ of cases of squamous cell carcinoma, and cutaneous types in approximately $50 \%$. In contrast, mucosal types occurred in less than $15 \%$ of cases. Codetection of one or more distinct HPV types within a single squamous cell carcinoma was seen in almost $60 \%$ of tumours. A similar trend was observed in basal cell carcinomas and premalignancies. Indeed, a consistent observation to emerge from all recent studies is that such mixed infection of single lesions is common and no one HPV type predominates in malignancies.

\section{PUVA treated patients}

Psoralen and ultraviolet A (PUVA) photochemotherapy is associated with a dose dependent increase in the risk of non-melanoma skin cancer in patients treated for psoriasis. ${ }^{37}$ Like ultraviolet $\mathrm{B}$ radiation, PUVA is both mutagenic and immunosuppressive and may thus act as a complete carcinogen. ${ }^{38-41}$ However, a cofactor role for HPV infection is suggested by the reversal of the usual basal cell to squamous cell carcinoma ratio observed in this group, just as in renal transplant recipients. We have recently analysed a series of PUVA related benign and malignant lesions ${ }^{42}$ and found HPV DNA sequences in 15 of 20 non-melanoma skin cancers, seven of 17 dysplastic PUVA keratoses, four of five skin warts, and four of 12 PUVA exposed normal skin samples. The majority of HPV positive lesions contained EV related HPV including HPV-5, -20, -21, -23, -24 , and -38 . Possible novel EV types were identified in further lesions. Mixed infection with cutaneous and mucosal types of epidermodysplasia verruciformis was present in six of $30 \mathrm{HPV}$ positive lesions. HPV-41 and HPV16/18 have been found in other PUVA associated squamous cell carcinomas in smaller studies. ${ }^{43-46}$ Thus the prevalence and type of HPV infection in cutaneous lesions from PUVA treated patients is similar to that reported in renal transplant associated skin lesions.

\section{HIV infection}

The gradual loss of immunity in AIDS produces increasing susceptibility to viral infection. HPV is perhaps the most common virus to produce mucocutaneous lesions in these patients, with a reported prevalence of between $5 \%$ and $27 \% .{ }^{47}$ Common and plantar warts are increased in frequency and may show histological evidence of dysplasia. ${ }^{48}$ EV-like skin lesions have also been reported, and in two cases the presence of HPV-5 and HPV- 8 was confirmed. ${ }^{49}$

Non-melanoma skin cancer in AIDS patients has not been comprehensively studied but it remains likely that long term survivors will be at increased risk. One small study of non-melanoma skin cancer from HIV infected patients ${ }^{50}$ found HPV DNA in two of 10 cutaneous squamous cell carcinomas using the suboptimal dot-blot method (with probes to mucosal genital types only) and three sets of consensus primers designed primarily for detection of mucosal HPV. We would anticipate finding a much higher prevalence of diverse HPV types in such lesions using a more comprehensive degenerate primer based method.

NON-MELANOMA SKIN CANCER IN THE GENERAL POPULATION

Most of the available data on the association of HPV and non-melanoma skin cancer in the general population are in the form of isolated case reports or small case series. ${ }^{34}{ }^{35}$ These have invariably been undertaken using a limited number of HPV probes that are not informative for the majority of HPV types and have therefore underestimated the true prevalence of HPV in cutaneous lesions. This is frequently compounded by the use of paraffin embedded material which yields suboptimal results compared with fresh frozen tissue. ${ }^{37}$

The most comprehensive studies to date using degenerate PCR detection methods have shown HPV DNA in up to $40 \%$ of fresh frozen tumours from immunocompetent individuals. Sixteen degenerate primer combinations were used in one study ${ }^{9}$ to identify HPV DNA in 
eight of 25 squamous cell carcinomas, four of 11 basal cell carcinomas, and two of four keratoacanthomas. A broad spectrum of different HPV was found including EV associated types $(8,9,23$, and 25$)$, common cutaneous types (4 and 7$)$, and low risk mucosal types (6b, 32, 34, and 42). HPV 51 was the only high risk mucosal type detected. Two novel HPV types were detected, one related to HPV 48 and the other to HPV 68. In a second study (Berkhout RJM et al, unpublished), a nested PCR designed to detect EV types was used. With this approach, EV-verruciformis HPV DNA only was detected in one of three cases of Bowen's disease, 10 of 19 squamous cell carcinomas, and 10 of 31 basal cell carcinomas. Five EV-associated HPV types (HPV-15, -20, -23, -25 , and -36) and nine putative novel EV related HPV types were identified.

Although the overall detection rate in these two studies is similar, the spectrum of HPV types clearly differs, again most likely reflecting differences in the specificities and sensitivities of the PCR primers used. Using our combined methodology ${ }^{36}{ }^{42}$ capable of detecting a broader spectrum of cutaneous, EV, and mucosal HPV types to equivalent sensitivity, preliminary data on non-melanoma skin cancers from immunocompetent individuals indicate a similar HPV DNA prevalence: viral DNA was detected in 15 of 23 squamous cell carcinomas and 12 of 33 basal cell carcinomas. EV-HPV types predominated over cutaneous and mucosal types, and mixed infections were less common than in immunosuppressed patients (unpublished data).

\section{Conclusions}

The study of HPV in non-melanoma skin cancer has been limited by the detection methods available until very recently. With the development of degenerate PCR methods a high prevalence and a broad spectrum of HPV types has now been found in premalignant and malignant lesions from both immunosuppressed and non-immunosuppressed individuals. In anogenital cancer there is a specific association of certain high risk HPV types and malignancy. In addition epidemiological, molecular, and functional data fulfil the WHO criteria for viral carcinogenesis. ${ }^{51}$ These criteria are far from met in non-melanoma skin cancer; there is little on the epidemiology of cutaneous and EV associated HPV types and many HPV found in skin cancer have a low transforming potential in vitro. Nonetheless the high prevalence of HPV DNA in non-melanoma skin cancer is provocative despite a lack of mechanistic data. Future research may identify new cellular targets for HPV oncoproteins that prove to be relevant to skin cancer, either independently or in interaction with ultraviolet radiation.

1 Ko CB, Walton S, Keczkes K, et al. The emerging epidemic of skin cancer. Br f Dermatol 1994;130:269-72.

2 Leigh IM, Newton Bishop JA, Kripke ML. Skin cancer. In: Leigh IM, Newton Bishop JA, Kripke ML, eds. Cancer surLeigh IM, Newton Bishop JA, Kripke ML, eds. Cancer sur-
veys, vol 26. New York: Cold Spring Harbour Laboratory veys, vol 26. New

3 Frost CA, Green AC. Epidemiology of solar keratosis. $\mathrm{Br} \mathcal{F}$ Dermatol 1994;131:455-64.
4 Ziegler A, Lefell DJ, Kunala S, et al. Mutation hotspots due to sunlight in the p53 gene of nonmelanoma skin cancers. Proc Natl Acad Sci USA 1993;90:4216-20.

5 Rees J. Genetic alterations in non-melanoma skin cancer. $\mathcal{f}$ Invest Dermatol 1994;103:747-50.

6 Zur Hausen H. Papillomavirus infections - a major cause of human cancers. Biochim Biophys Acta 1996;1288:F55-78.

7 Majewski S, Jablonska S. Epidermodysplasia verruciformis as a model of human papillomavirus-induced genetic cancer of the skin. Arch Dermatol 1995;131:1312-18.

8 Shamanin V, Glover M, Rausch C, et al. Specific types of human papillomavirus found in benign proliferations and carcinomas of the skin in immunosuppressed patients. Cancer Res 1994; 54:4610-13.
Cancinas of the skin in

9 Shamanin V, zur Hausen H, Lavergne D, et al. Human paplomavirus infections in non-melanoma skin cancers from renal transplant recipients and non-immunosuppressed patients. F Natl Cancer Inst 1996;88:802-11.

10 Berkhout RJM, Tieben LM, Smits HL, et al. Nested PCR approach to detection and typing of epidermodysplasia verruciformis-associated human papillomavirus types in cutaneous cancers from renal transplant recipients. F Clin Microbiol 115;33:690-5.

11 de Jong-Tieben LM, Berkhout RJM, Smits HL, et al. High frequency of detection of epidermodysplasia verruciformisassociated human papillomavirus DNA in biopsies from malignant and premalignant skin lesions from transplant recipients. F Invest Dermatol 1995;105:367-71.

12 De Villiers E-M, Lavergne D, Mclaren K, et al. Prevailing papillomavirus types in non-melanoma carcinomas of the kin in renal allograft recipients. Int f Cancer 1997;73:356 61.

13 de Villiers E-M. Human pathogenic papillomavirus types: an update. Curr Top Microbiol Immunol 1994;186:1-12.

4 Chan SY, Delius H, Halpern AL, et al. Analysis of genomic sequences of 95 papillomavirus types: uniting typing, phylogeny and taxonomy. F Virol 1995;69:3074-83

15 Lewandowsky F, Lutz W. Ein Fal einer bisher nich beschrieben Hauterkrankung (epidermodysplasia verruciformis). Arch Dermatol Syphilol 1922;141:193-203.

16 Orth G. Epidermodysplasia verruciformis: a model for understanding the oncogenicity of human papillomaviruses. In: Ciba Foundation Symposium 1984;120:157-74.

17 Cooper KD, Androphy EJ, Lowy D, et al. Antigen presentaion and $\mathrm{T}$ cell activation in epidermodysplasia verruciformis. F Invest Dermatol 1990;94:769-76.

18 Woodworth CD, Doniger J, DiPaolo JA. Immortalization of human foreskin keratinocytes by various human papillomavirus DNAs corresponds to their association with cervical carcinoma. F Virol 1989;63:159-64.

19 Iftner T, Bierfelder S, Csapo Z, et al. Involvement of the human papillomavirus type 8 genes E6 and E7 in transformation and replication. $\mathcal{F}$ Virol 1988;62:3655-61.

20 Kiyono T, Nagashima K, Ishibashi M. The primary structure of major viral RNA in a rat cell line transfected with type 47 human papillomavirus DNA and the transforming activity of its cDNA and E6 gene. Virology 1989;173:551-65.

21 Steger G, Pfister H. In vitro expressed HPV8 E6 protein does not bind p53. Arch Virol 1992;125:355-60.

22 Seeberger R, Haugen T, Turek L, et al. An enhancer of human papillomavirus type 8 is trans-activated by the bovine papillomavirus type $1 \mathrm{E} 2$ function. In: Steinberg BM, Brandsma JL, Taichman LB, eds. Papillomaviruses: cancer cells, vol 5. New York: Cold Spring Harbor Laboratory, 1987:33-8.

23 May M, Grassman K, Pfister H, et al. Transcriptional silencer of the HPV 8 later promotor interacts alternatively with the viral transactivator E2 or with cellular factor. $\mathcal{F}$ Virol 1994;68:3612-19.

24 Walder BK, Robertson MR, Jeremy D. Skin cancer and immunosuppression. Lancet 1971;ii:1282-3.

25 Birkeland SA, Storm HH, Lamm LU, et al. Cancer risk after renal transplantation in the Nordic countries, 1964-1986. Int 7 Cancer 1995;60:183-9.

26 Shiel A, Flavel S, Disney A, et al. Cancer development in patients progressing to dialysis and renal transplantation. Transplant Proc 1985;17:1685-8.

27 Hardie IR, Strong RW, Hartley LC, et al. Skin cancer in Caucasian renal allograft recipients living in a subtropical climate. Surgery 1989;87:177-83.

28 Hartevelt MM, Bavinck JN, Kootte AM, et al. Incidence of skin cancer after renal transplantation in The Netherlands. Transplantation 1990;49:506-9.

29 London NJ, Farmery SM, Will EJ, et al. Risk of neoplasia in renal transplant patients. Lancet 1995;346:403-6.

30 Boyle J, McKie R, Briggs J, et al. Cancer, warts and sunshine in renal transplant recipients: a case control study. Lancet $1984 ; \mathrm{i}: 702-5$

31 Blessing K, McClaren KM, Benton EC, et al. Histopathology of skin lesions in renal allograft recipients: an assessment of viral features and dysplasia. Histopathology 1989;14:129-39.

32 Benton C, Shahidullah H, Hunter JAA. Human papillomavirus in the immunosuppressed. Papillomavirus Rep 1992;2: 23-6.

33 Glover MT, Proby CM, Leigh IM. Skin cancer in renal transplant patients. Cancer Bull 1993;45:220-4.

34 McGregor JM, Proby CM. The role of papillomaviruses in human non-melanoma skin cancer. In: Leigh IM, Newton Bishop JA, Kripke ML, eds. Cancer surveys: skin cancer, vol 26. New York: Cold Spring Harbour Laboratory Press, 1996:219-36. 
35 Proby C, Storey A, McGregor J, et al. Does human papillomavirus infection play a role in non-melanoma skin cancer? Papillomavirus Rep 1996;7:53-60.

36 Storey A, Thomas M, Kalita A, et al. Role of a 553 polymorphism in the development of human papillomavirusassociated cancer. Nature 1998;393:229-34.

37 Studniberg HM, Weller P. PUVA, UVB, psoriasis and nonmelanoma skin cancer. $\mathcal{F}$ Am Acad Dermatol 1993;29:101322.

38 Young AR. Photocarcinogenecity of psoralens used in PUVA treatment: present status in mouse and man. $\mathcal{F}$ Photochem Photobiol B:Biol 1990;6:237-47.

39 Nataraj AJ, Wolf P, Cerroni L, et al. p53 Mutation in squamous cell carcinomas from psoriasis patients treated with psoralen + UVA (PUVA). 7 Invest Dermatol 1997;109: 238-43.

40 Ullrich SE. Systemic immunosuppression of cell-mediated immune reactions by a monofunctional psoralen plus
ultraviolet A radiation. Photodermatol Photoimmunol Photomed $1991 ; 8: 116-22$.

41 Kripke ML, Morison WL, Parrish JA. Systemic suppression of contact hypersensitivity in mice by psoralen plus UVA of contact hypersensitivity in mice by psoralen plus

radiation (PUVA). F Invest Dermatol 1983;81:87-92.
42 Harwood CA, Spink PJ, Surentheran T, et al. Detection of human papillomavirus DNA in PUVA-associated nonmelanoma skin cancers. F Invest Dermatol 1998;111:123-7.

43 Weinstock MA, Coulter S, Bates J, et al. Human papillomavirus and widespread cutaneous carcinoma after PUVA photochemotherapy. Arch Dermatol 1995;131:701-4.

44 Rubben A, Baron JM, Grussendorf-Conen E-I. Demonstration of human papillomavirus type 16-related DNA and absence of detectable p53 gene mutations in widespread cutaneous squamous cell carcinomas after oral psoralen

45 wayle-Lebey P, Labadies P, Basset-Seguin N, et al. Bayle-Lebey $\mathrm{P}$, Labadies P, Basset-Seguin $\mathrm{N}$, et al.
Carcinomes cutanés et papillomavirus 5. Révélation lors d'une photochimiothérapie UVA prolongée. Ann Dermatol Venereol 1994;121:496-8.

46 Hirt L, Hirsch-Behnam A, de Villiers E-M. Nucleotide sequence of human papillomavirus (HPV) type 41: an unusual HPV type without typical E2 binding site consensus sequence. Virus Res 1990;18:179-90.

47 Penneys NS. Cutaneous viral disease in AIDS. In: Penneys NS, ed. Skin manifestations of AIDS, 2nd ed. London: Martin Dunitz, 1995:84-91.

48 Milburn PB, Brandsma JL, Goldsman CI, et al. Disseminated warts and evolving squamous cell carcinoma in a patient with acquired immunodeficiency syndrome. $\mathcal{F} \mathrm{Am}$ Acad Dermatol 1988;19:401-5.

49 Berger TG, Sawchuk WS, Leonardi C, et al. Epidermodysplasia verruciformis-associated papillomavirus infection plasia verruciformis-associated papillomavirus infection Demplicating human immu 1991;124:79-83.

50 Maurer TA, Vin Christian K, Kerschmann RL, et al. CutaMaurer TA, Vin Christian K, Kerschmann RL, et al. Cuta-
neous squamous cell carcinoma in human immunodeficiency virus-infected patients. A study of epidemiologic risk factors, human papillomavirus, and p53 expression. Arch Dermatol 1997;133:577-83.

51 International Agency for Research on Cancer. IARC monographs on the evaluation of the carcinogenic risk to humans, vol 64. Human papillomaviruses. Lyons: International Agency for Research on Cancer, 1995:196-212. 